\title{
Comparing Subsurface Energy Storage Systems: Underground Pumped Storage Hydropower, Compressed Air Energy Storage and Suspended Weight Gravity Energy Storage
}

\author{
Javier Menéndez ${ }^{1, *}$, Falko Schmidt $^{2}$, Jorge Loredo ${ }^{3}$ \\ ${ }^{1}$ Hunaser Energy, 33005 Oviedo, Spain \\ ${ }^{2}$ Mining Engineer, 39011, Santander, Spain \\ ${ }^{3}$ University of Oviedo, Mining Exploitation Department, 33004 Oviedo, Spain
}

\begin{abstract}
In the current energy context, intermittent and non-dispatchable renewable energy sources, such as wind and solar photovoltaic (generation does not necessarily correspond to demand), require flexible solutions to store energy. Energy storage systems (ESS) are able to balance the intermittent and volatile generation outputs of variable renewable energies (VRE). ESS provide ancillary services such as: frequency, primary and voltage control to the power grid. In order to fulfil the power system control, ESS can switch within seconds for different operation modes. Many times, ESS imply environment impacts on landscape and society. To solve this problem, disused underground spaces, such as closed mines, can be used as underground reservoir for energy storage plants. In this paper, a comparative analysis between underground pumped storage hydropower (UPSH), compressed air energy storage (CAES) and suspended weight gravity energy storage (SWGES) with suspended weights in abandoned mine shafts is carried out. Pumped storage hydropower (PSH) is the most mature concept and account for $99 \%$ of bulk storage capacity worldwide. The results obtained show that in UPSH and CAES plants, the amount of stored energy depends mainly on the underground reservoir capacity, while in SWGES plants depends on the depth of the mine shafts and the mass. The energy stored in a SWGES plant (3.81 $\mathrm{MWh} \mathrm{cycle}^{-1}$ with $600 \mathrm{~m}$ of usable depth assuming 3,000 tonne suspended weight) is much lower than UPSH and CAES plants.
\end{abstract}

\section{Introduction}

In 2017, electricity generation from renewable energy sources (RES) contributed $30.7 \%$ to total EU-28 gross electricity consumption [1]. The intermittent nature of some RES, such as wind and solar photovoltaic requires flexible ESS. An UPSH scheme, CAES plants and SWGES system are effectively a large storage battery.

PSH is the most mature technology and account for $99 \%$ of bulk storage capacity worldwide [2], because allows large amounts of energy to be stored and generated. PSH plants imply environment impacts on landscape and society [3]. An alternative could be UPSH plants in disused mining structures. Although some studies have considered the use of underground reservoirs [2, 3-10], however until now there have been no known projects of this type under operation.

Currently, there are two diabatic CAES plants in operation in the world. The first operational CAES plant was the $321 \mathrm{MW}$ of output power Huntorf plant in Germany, using abandoned underground salt caverns. The second is the 110 MW plant with a rated energy capacity of 26 hours in McIntosh (USA). Many studies have been carried out to analyze the implementation of CAES plants in disused underground spaces [11-14], but no plants have been built yet.
This paper analyzes different ways of storing energy in disused underground spaces. UPSH, CAES and SWGES plants are studied in order to know the amount of energy produced by each of them, and what are the most important factors that influence the capacity to store subsurface energy in closed underground mines.

\section{Materials and methods}

\subsection{Underground pumped-storage hydropower system}

UPSH plants consist in two reservoirs, the upper reservoir is located at the surface, while the lower reservoir is underground. During periods of low demand, energy from the transmission grid is used to pump water from the lower reservoir (underground) to the upper reservoir (surface). During periods of peak electricity demand, the process is reversed and stored water flows to the lower reservoir through Francis turbines driving generators. Fig. 1 shows a schematic diagram of the UPSH system. The penstock is located in current vertical shafts, and the powerhouse cavern (Francis pumpturbine and motor-generator) and the lower reservoir are underground.

Corresponding author: javiermenendezr@gmail.com 


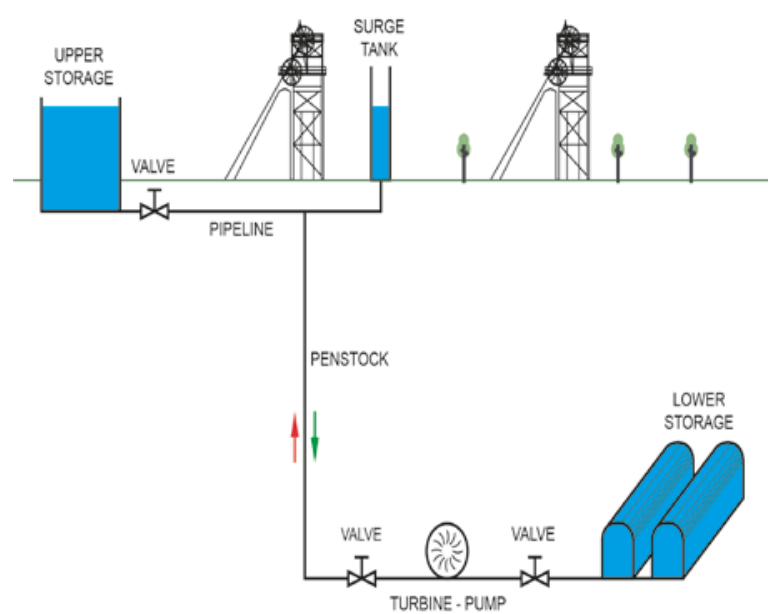

Fig. 1. Schematic diagram of the underground pumped storage hydropower system. Upper reservoir is located at the surface and lower reservoir is underground (network of tunnels).

The energy storage capacity of the underground pumped storage hydropower system depends on the reservoir capacity and net head [11], and it is given by Eq. (1).

$$
E_{U P S H}=g \cdot V \cdot H \cdot \eta \cdot \alpha
$$

where $E_{U P S H}$ is the stored energy (MWh per cycle), $g$ is the acceleration due to gravity, $V$ is the capacity of the reservoir $(\mathrm{kg}), \mathrm{H}$ is the net head $\left(\mathrm{mH}_{2} \mathrm{O}\right), \eta$ is the efficiency of the Francis pump-turbine (turbine mode), which is assumed to be 0.9 , and $\alpha=2.7 e^{-10}$, which is the unit conversion factor ( $/ \mathrm{MWh}$ ).

\subsection{Compressed air energy storage system}

CAES systems store energy in the form of compressed air (i.e. potential elastic energy) in an underground reservoir and works in a similar way to conventional gas turbines [11]. Ambient air $\left(20{ }^{\circ} \mathrm{C}, 101,325 \mathrm{~Pa}\right)$ is compressed and stored under pressure (40-75 bar) in an underground cavern. To charge a CAES system, excess or off-peak power is directed towards a motor (energy consumption) that drives a chain of compressors to store air in the cavern (e.g. salt caverns). When discharging, the compressed air is released from the subsurface reservoir, cooling down in the process. This is achieved by mixing compressed air with fuel in a combustion chamber that drives the turbine system (energy generation). Fig. 2 shows a diagram of the CAES plants using underground caverns as compressed air reservoir.

The energy storage capacity of the compressed air energy storage system using closed underground mines as compressed air reservoir is given by Eq. (2).

$$
E_{C A E S}=\left[\left(\dot{m}_{a}+\dot{m}_{F}\right) \cdot\left(h_{3}-h_{4}\right) \cdot \eta \cdot t\right] \cdot \alpha
$$

where $E_{C A E S}$ is the stored energy (MWh per cycle), $\dot{m}_{a}$ is the air mass flow, $\dot{m}_{F}$ is the fuel mass flow (e.g. natural gas), $h_{3}$ and $h_{4}$ are the enthalpies in expansion stage (gas turbine), $\eta$ is the gas turbine efficiency, which is assumed to be $0.8, t$ is the cycle time, and $\alpha=1 e^{-3}$, which is the unit conversion factor (kWh/MWh).

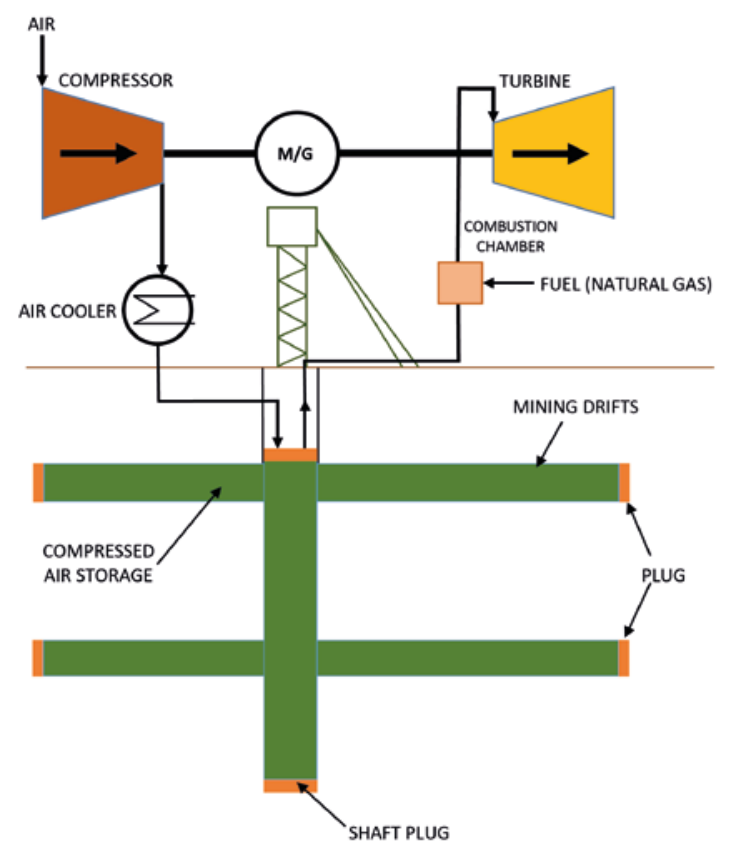

Fig. 2. Schematic diagram of the compressed air energy storage plant in closed underground mines. Turbine and compressor located at the surface and underground compressed air reservoir.

\subsection{Suspended weight gravity energy storage}

Fig. 3 shows a schematic diagram of the SWGES system in abandoned mine shafts. Currently, there are no SWGES plants under operation. Energy is stored by drawing power from the electrical grid to lift the suspended weight [15]. The main components of the SWGES system are:

- $\quad$ The vertical mine shafts in closed mines.

- $\quad$ The suspended weight (cylindrical weight).

- A motor connected to the cylindrical weight by wire ropes.

- Connections and guidance system.

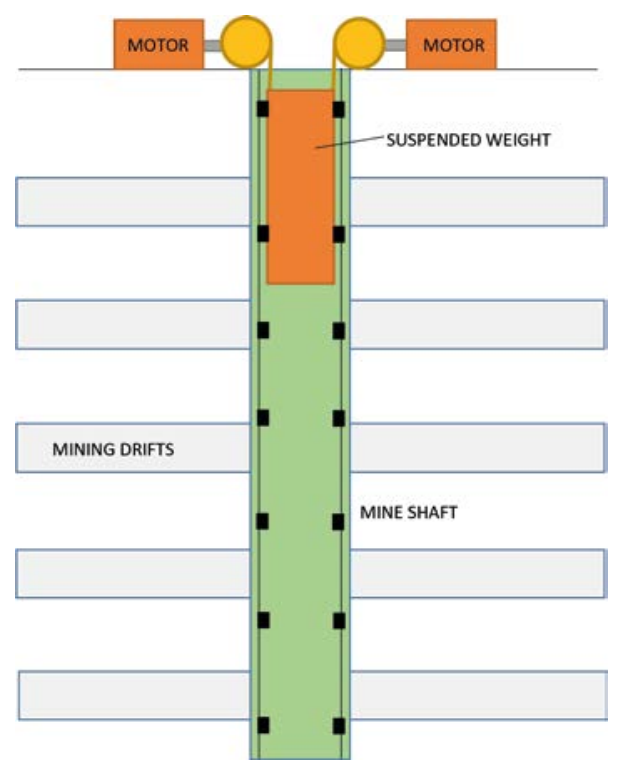

Fig. 3. Schematic diagram of the gravity energy storage system with suspended weights in abandoned mine shafts. 
The energy storage capacity of the gravity energy storage with suspended weights in disused mine shafts is given by Eq. (3).

$$
E_{S W G E S}=\eta \cdot g \cdot m \cdot d \cdot \alpha
$$

where $E_{S W G E S}$ is the stored energy (MWh per cycle), $\eta$ is the round-trip efficiency, which is assumed to be 0.8 , $g$ is the acceleration due to gravity, $m$ is the mass of the suspended weight $(\mathrm{kg}), d$ is the usable depth of the mine shaft $(\mathrm{m})$, and $\alpha=2.7 e^{-10}$, which is the unit conversion factor (J/MWh).

\section{Results and discussion}

An analysis of electricity production has been carried out for UPSH, CAES and SWGES plants. Fig. 4 shows the energy production in an UPSH plant. Underground water reservoir between 0.1 and $0.5 \mathrm{Mm}^{3}$ and hydraulic net head between 100 and $600 \mathrm{mH}_{2} \mathrm{O}(58.84$ bar) have been considered. The production of electricity (turbine mode) has been calculated using Eq. (1).

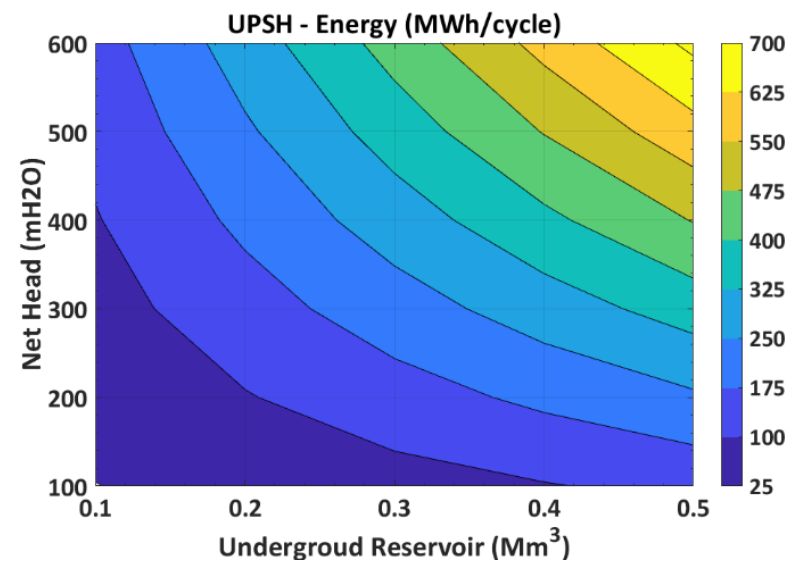

Fig. 4. Energy storage per cycle of an UPSH plant as a function of water storage capacity and net head, considering a Francis turbine efficiency of $90 \%$.

The output power of an UPSH depends on the cycle time at full load. When the cycle time increases, the water flow rate decreases, and therefore, the output power also decreases. However, the stored energy does not depend on the cycle time. Fig. 5 shows the energy production in a CAES plant. Underground reservoir between 0.1 and $0.25 \mathrm{Mm}^{3}$ and gas turbine temperature between 1,000 and 1,200 $\mathrm{K}$ have been considered. The production of electricity has been calculated using Eq. (2).

Fig. 6 shows the energy production in a SWGES plant. Mass of the suspended weight between 250 and 3,000 $\mathrm{t}$ and usable depth between 100 and $600 \mathrm{~m}$ have been considered. The stored energy has been calculated using Eq. (3). The typical cycle time used for this type of facilities is between 0.25 and $2 \mathrm{~h}$ with a maximum acceleration of $0.3 \mathrm{~m} \mathrm{~s}^{-2}$.

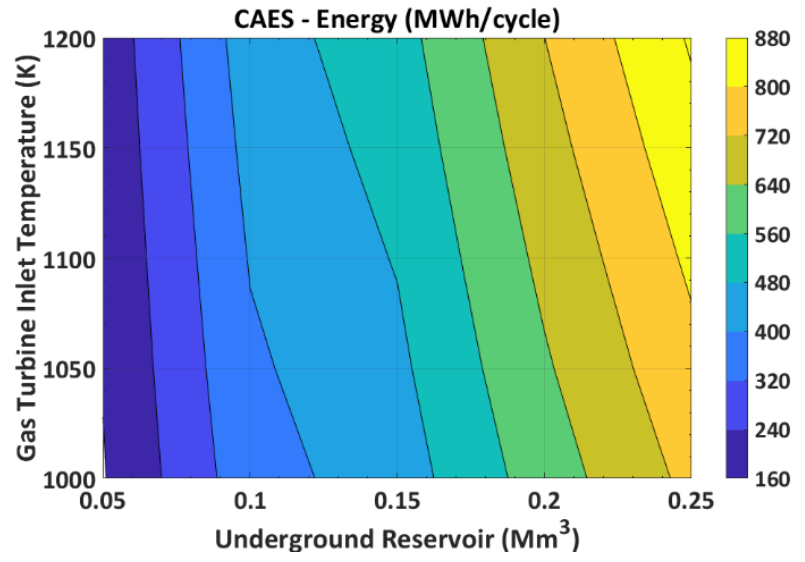

Fig. 5. Energy storage per cycle of a CAES plant as a function of storage capacity and gas turbine inlet temperature, considering a gas turbine efficiency of $80 \%$.

The stored energy in a SWGES plant is much lower than UPSH or CAES plants. Considering a mass of suspended weight of 3,000 $\mathrm{t}$ and $600 \mathrm{~m}$ of usable depth, the generation of electricity is $3.81 \mathrm{MWh}$ per cycle.

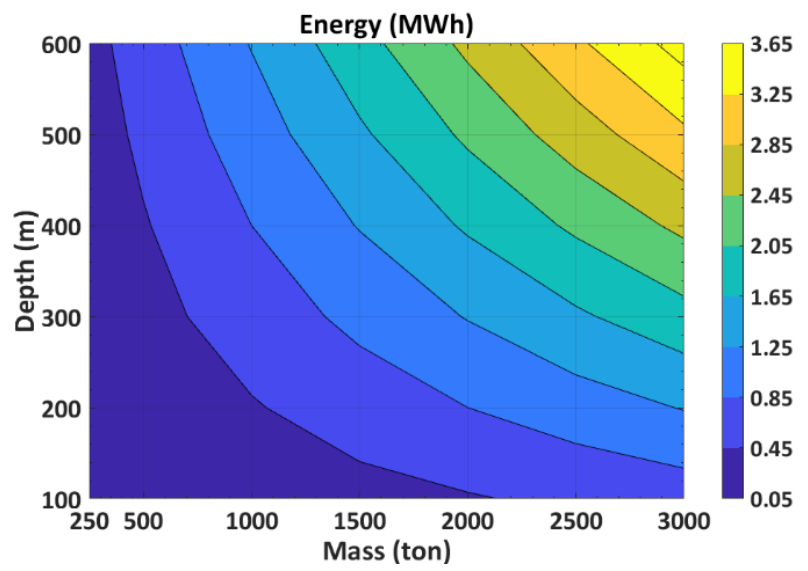

Fig. 6. Energy storage per cycle for SWGES plants as a function of mass of suspended weight and depth of disused mine shafts.

\section{Conclusions}

The intermittent nature of some renewable energies, such as wind and solar photovoltaic, is making ESS and other flexibility options increasingly necessary. ESS provide ancillary services such as: frequency, primary and voltage control to the power electrical grid.

An alternative to reduce the environmental impacts on landscape and society in comparison with conventional ESS is to use disused underground space (e.g. closed underground mines) to store energy. UPSH, CAES and SWGES systems have been analyzed in order to know the amount of stored energy by each of them. An underground water reservoir of $0.5 \mathrm{Mm}^{3}$ and a net head of $600 \mathrm{mH}_{2} \mathrm{O}$ (58.84 bar) for UPSH, $0.25 \mathrm{Mm}^{3}$ for CAES (compressed air reservoir), and 3,000 tonne suspended weight and $600 \mathrm{~m}$ depth for SWGES have been considered. Energy storage per cycle of 717, 880 and 3.81 MWh has been estimated for UPSH, CAES and SWGES systems, respectively. 


\section{References}

1. International Energy Agency (IEA). Key world energy trends, except from: renewables information.

2. Winde F, Kaiser F, Erasmus E. Exploring the use of deep level gold mines in South Africa for underground pumped hydroelectric energy storage schemes. Renew Sustainable Energy Rev 2016;78:668-82.

https://dx.doi.org/10.1016/j.rser.2017.04.116.

3. Wong IH. An underground pumped storage scheme in the Bukit Timah Granite of Singapore. Tunn Undergr Sp Tech 1996;11(4):485-9. https://doi.org/10.1016/S0886-7798(96)00035-1.

4. Menendez J, Loredo J, Fernandez-Oro J, Galdo M. Underground pumped-storage hydro power plants with mine water in abandoned coal mines. In: Proceedings of the IMWA 13th International Congress, 2017; pp. 6-13.

5. Pickard WF. The history, present state, and future prospects of underground pumped hydro for massive energy storage. Proceedings of the IEEE 2012;100(2):473-83.

https://doi.org/10.1109/JPROC.2011.2126030.

6. Menendez J, Loredo J, Fernandez-Oro J, Galdo M. Energy storage in underground coal mines in NW Spain: Assessment of an underground lower water reservoir and preliminary energy balance. Renew. Energy 2019; 134:1381-1391.

https://doi.org/10.1016/j.renene.2018.09.042

7. Pujades E, Willems $\mathrm{T}$, Bodeux S, Orban $\mathrm{P}$, Dassargues A. Underground pumped storage hydroelectricity using abandoned works (deep mines or open pits) and the impact on groundwater flow. Hydrogeol $J$ 2016;24(6):1531-46. https://doi.org/10.1007/s10040-016-1413-z.

8. Menendez J, Loredo J. Use of closured open pit and underground coal mines for energy generation: Application to the Asturias Central Coal Basin (Spain). E3S Conferences, 2019;80:01005. https://doi.org/10.1051/e3sconf/20198001005
9. Menendez J, Fernandez-Oro JM, Galdo M, Loredo J. Pumped-storage hydropower plants with underground reservoir: Influence of air pressure on efficiency of the Francis turbine and energy production. Renew. Energy 2018; 143:1427-1438.

https://doi.org/10.1016/j.renene.2019.05.099

10. Pujades E, Orban P, Bodeux S, Archambeau P, Erpicum S, Dassargues A. Underground pumped storage hydropower plants using open pit mines: How do groundwater exchanges influence the efficiency?. Appl Energy 2017;190:135-46. https://doi.org/10.1016/j.apenergy.2016.12.093.

11. Menendez J, Ordóñez A, Álvarez R, Loredo J. Energy from closed mines: Underground energy storage and geothermal applications. Renew Sustainable Energy Rev 2019;108:498-512. https://doi.org/10.1016/j.rser.2019.04.007.

12. He W, Luo X, Evans D, Busby J, Garvey S, Parkes $D$ et al. Exergy storage of compressed air in cavern and cavern volume estimation of the large-scale compressed air energy storage system. Appl Energy 2017;208:745-757. https://doi.org/10.1016/j.apenergy.2017.09.074.

13. Lutynski M. An overview of potential benefits and limitations of Compressed Air Energy Storage in abandoned coal mines. IOP Conference Series: Mater Sci Eng 2017;268, conference 1. https://dx.doi.org/10.1088/1757899X/268/1/012006.

14. Perazzelli P, Anagnostou G. Design issues for compressed air energy storage in sealed underground cavities. J Rock Mech Geotech Eng 2016;8(3):314-28. https://doi.org/10.1016/j.jrmge.2015.09.006.

15. Morstyn T, Chilcott M, McCulloch MD. Gravity energy storage with suspended weights for abandoned mine shafts. Appl Energy. 2019;239:201206. https://doi.org/10.1016/j.apenergy.2019.01.226 